\title{
Editorial: Understanding the Impact and Invasion Success of Aquatic Non-native Species: How They Interact With Novel Environments and Native Biota
}

\author{
Ali Serhan Tarkan ${ }^{1,2}$, Baran Yoğurtçuoğlu ${ }^{3 *}$, Paraskevi K. Karachle ${ }^{4}$, Eleni Kalogianni ${ }^{4}$, \\ Nildeniz Top Karakuş ${ }^{1}$ and Elena Tricarico ${ }^{5}$ \\ ${ }^{1}$ Ecology \& Invasion Unit, Department of Basic Sciences, Faculty of Fisheries, Muğla Sıtkı Koçman University, Muğla, Turkey, \\ ${ }^{2}$ Department of Ecology and Vertebrate Zoology, Faculty of Biology and Environmental Protection, University of Łódz, Łódz, \\ Poland, ${ }^{3}$ Freshwater Fish Biology and Ecology Laboratory, Department of Biology, Faculty of Science, Hacettepe University, \\ Ankara, Turkey, ${ }^{4}$ Hellenic Centre for Marine Research, Institute of Marine Biological Resources and Inland Waters, Attica, \\ Greece, ${ }^{5}$ Department of Biology, University of Florence, Florence, Italy
}

Keywords: biological invasions, non-native species, invasive species, impact assessment, interactions

\section{OPEN ACCESS}

Edited and reviewed by: Orsolya Valkó, Hungarian Academy of Science, Hungary

*Correspondence: Baran Yoğurtçuoğlu yokbaran@gmail.com

Specialty section: This article was submitted to Conservation and Restoration

Ecology,

a section of the journa Frontiers in Ecology and Evolution

Received: 06 October 2021 Accepted: 13 October 2021 Published: 25 November 2021

Citation:

Tarkan AS, Yoğurtçuoğ/u B, Karachle PK, Kalogianni E, Top

Karakuş N and Tricarico E (2021)

Editorial: Understanding the Impact and Invasion Success of Aquatic

Non-native Species: How They Interact With Novel Environments and Native Biota.

Front. Ecol. Evol. 9:790540. doi: 10.3389/fevo.2021.790540

\section{Editorial on the Research Topic}

Understanding the Impact and Invasion Success of Aquatic Non-native Species: How They Interact With Novel Environments and Native Biota

\section{INTRODUCTION}

The introduction of non-native aquatic species through a wide range of human-induced pathways (e.g., fisheries, fish stocking, aquaculture, sport fishing, shipping, ornamental and aquarium fish trade, opening new inter-sea channels) is considered as a main driver of biodiversity loss and ecosystem services downgrading in aquatic ecosystems all over the world (García-Berthou et al., 2005; Katsanevakis et al., 2014; Havel et al., 2015). The current extent, frequency, and the rate of introduction of invasive species have dramatically increased in the recent years due to the higher mobilization and expanding demands in world-wide trade activities. While the spread of a species beyond its native range could be a natural process, proliferated intensity of human intervention in exploiting new ecosystems along with the effects of global climate change has long been thought to cause the increasing frequency of global invasions and range expansions of non-native species (Simberloff et al., 2013; Vilizzi et al., 2021).

It is a generally disregarded fact that not all non-native species are a threat to their hosting ecosystems. However, we should note those that may become invasive. The term "invasive" has been described in various ways but should refer to the non-native species that have proved to cause detrimental impacts on biodiversity and ecosystem services (Rejmánek, 2011). To understand whether a non-native species exhibits invasive characteristics, a wider set of detailed information on its specific impacts through field and experimental studies is needed. This is even more demanding for some invasive aquatic species that should be assessed on multiple scales. The other species present in the invaded environment, regardless of being native or non-native, are also expected to play a key role in the magnitude of the impacts of a new invader. Therefore, one of the most complex issues is to predict the ways in which introduced species can influence native communities under the diverse and stochastic nature of interactions within the environment that is novel to the invader 
(Blossey, 2011), and how they can interact with other non-native species originating from different areas. Hence, standardized methods to assess impacts are rather hard to be developed as data on specific effects of invasive species are barely available and the nature of these impacts is variable. In this regard, it is essential to take up evidence-based science to drive better-informed policy and economic models so as to provide a more sustainable balance between ecosystem services and the conservation/protection of native/endemic species and fragile ecosystems.

To address these issues, our Research Topic titled "Understanding the Impact and Invasion Success of Aquatic Non-native Species: How They Interact with Novel Environments and Native Biota," compiled a series of research studies providing new data and approaches in assessing the invasion success and the impacts of various non-native species in the different regions of the world belonging to various groups of organisms and from various environments. A range of invasion ecology specialists endeavored to provide up-to-date information on the multifaceted issues of non-native species introductions and to map conservation priorities in terms of biological invasion. A total of 10 articles, including original pieces of research, a review, a brief research report and a hypothesis and theory, are included as part of this Research Topic. Below, an overview of these articles is provided.

\section{RESEARCH TOPIC OVERVIEW}

While the articles in this Research Topic can be roughly grouped based on their primary focus on the type of the organisms or environments, we follow an organization of the showcase with topics ranging from studies on single species to communities and, finally, to theoretical and modeling ones.

Atalah et al. quantified the ecological impacts of the Mediterranean fanworm (Sabella spallanzanii), an undesired invasive species in New Zealand, by investigating the diversity and abundance of benthic communities using a manipulative field experiment. Their research revealed compositional differences of benthic communities when exposed to $S$. spallanzanii. They concluded that the negative impacts have the potential to reach up to functioning of soft-sediment habitats through alterations to nutrient cycling, bioturbation, and benthic-pelagic coupling. Rolla et al. (1) assessed the extent of spatiotemporal variation in the growth and settlement rates of zebra mussel (Dreissenapolymorpha) in a recently colonized artificial lake area in the UK, aiming to better understand its establishment to propose more efficient management options. For control measures, they suggested that removal of mussels in deep waters might be beneficial during the summer and early autumn but depending on local conditions due to the existence of contrasting density-dependent mechanisms. Rolla et al. (2) investigated the variation in the trophic ecology of top mouth gudgeon (Pseudorasbora parva), the most invasive freshwater fish in Europe, in four contrasting freshwater habitats in South Wales, using stable isotope data and stomach content data as a complementary tool. Their study revealed great variation in diet and trophic position between neighboring waters even only a few kilometers apart. They also found higher diversity in the diet and a more generalist pattern in ponds containing fewer competitors, on the other hand, a poor condition and low-trophic position in the ponds with other cyprinids. Hudson et al. reviewed the genetic, genomic, and phenotypic pieces of research on three-spine stickleback (Gasterosteus aculeatus) in Central Europe, focusing on Switzerland and the invasion of the Lake Constance region. In the Lake Constance region, they found rapid phenotypic and genetic divergence between a lake population and some stream populations; and, also, considerable phenotypic variation within the lake population itself, alongside their attempt to document and discuss the complex colonization history, and trace the invasion pathways of stickleback. Haubrock et al. investigated the trophic interactions of the invasive alien species in the Arno River (Tuscany, Italy) using stable isotopes and dietary analyses. Their results suggested that species sharing close geographic origin (or shared histories of co-evolution) would exhibit a lower potential to compete than species from different origins, which affect their potential impact on native species. Jurlina et al. addressed the potential interactions between the native and alien trout groups (Salmo spp.) within the western part of the Balkans. Their study focused on the alternative life histories (e.g., occurrence of migratory behavior), cross-breeding, and introgression between the alien and native populations. Their results showed the occurrence of cross-breeding and introgression of genes between some of the alien and native populations. They concluded that migratory behavior might have two contrary consequences; i.e., it provides native trout stocks an alternative way to cope with the alien strains and/or species introduced into their home streams but also enables non-native brown trout to intrude into the recipient streams and introgress into their resident trout stocks. McCarthy et al. dealt with one of the poorly studied impacts of non-native species, i.e., their roles in changing biogeochemical processes, such as the emission of greenhouse gases (GHGs). They compared emissions of nitrous oxide $\left(\mathrm{N}_{2} \mathrm{O}\right)$, methane $\left(\mathrm{CH}_{4}\right)$, and carbon dioxide $\left(\mathrm{CO}_{2}\right)$ produced by a native (Crassostrea virginica) and non-native (Ostrea edulis) oyster species. They briefly reported that the non-native oyster is a lower GHG emitter than the native one and emphasize that, at least in terms of GHG emissions, this non-native species introduction may not be detrimental to the environment. Their results also showed that GHG fluxes and chlorophyll-a consumption rates were not driven by a common set of environmental parameters, nor did fluxes vary consistently with oyster characteristics. South et al. evaluated the competitive interaction indirectly by comparing the closing force of two invasive crayfish species (Cheraxquadricarinatus and Procambarusclarkii) with a native analogous freshwater crab (Potamonautesperlatus). Their results suggested that the native crab had the capacity to hold a competitive mechanical advantage, a kind of biotic resistance toward both invaders, but that this varies with sex.

Finally, two articles contributed by their modeling approaches. Copp and Fox took up a critical perspective and reviewed their own model developed in 2007. The model is applied to non-native populations of pumpkinseed (Lepomisgibbosus) in nine countries of Europe and western 
Asia by aiming to estimate the efficiency of the model for predicting the potential invasiveness of non-native freshwater fish populations. Their model was not strongly supported in their tests with the pumpkinseed likely due to the shortcomings in the dataset they used, as well as the uncertainty of the source populations. Yet, they concluded that, as long as the size and the quality of the life-history database are sufficient, such life-history models can be useful for predicting invasiveness status in non-native freshwater fishes. Yogurtçuoglu et al. addressed the establishment and invasiveness potential of the rainbow trout (Oncorhynchus mykiss) in Turkey, where it is the most cultured non-native fish species. They proposed an integrated approach in which habitat suitability and invasiveness risk assessment are used together to identify its geographic overlap probability with the native salmonid species of conservation concern. They further proposed a metric by blending the benefited risk assessment approach with the spatial analysis of the native trout species to prioritize and categorize the sensitivity of native salmonids against the overlap and interaction (including hybridization) with rainbow trout. Their results suggested that the northern region is the most suitable area for the rainbow trout, and Salmo abanticus, one of the endangered native trout, had the highest vulnerability and priority in conservation sense.

\section{CONCLUSIONS}

Conservationists are expected to elucidate the relations between the level and nature of propagule pressure from non-native

\section{REFERENCES}

Blossey, B. (2011). "Enemy release hypothesis" in Encyclopedia of Biological Invasions, eds D. Simberloff and M. Rejmánek (Berkeley; LosAngeles, CA: University of California Press), 193-196.

García-Berthou, E., Alcaraz, C., Pou-Rovira, Q., Zamora, L.,Coenders, G.,and Feo, C. (2005). Introduction pathways and establishment rates of invasive aquatic species in Europe. Can. J. Fish. Aquat. Sci. 62, 453-463. doi: 10.1139/f05-017

Havel, J. E., Kovalenko, K. E.,Thomaz, S. M., Amalfitano, S. and Kats, L. B.(2015). Aquatic invasive species: challenges for the future. Hydrobiologia 750, 147-170. doi: 10.1007/s10750-014-2166-0

Katsanevakis, S., Wallentinus, I. Zenetos, A., Leppäkoski, E., Çinar, M. E., Öztürk, B., Grabowski, M., et al. (2014). Impacts of invasive alien marine species on ecosystem services and biodiversity: a pan-European review. Aquat. Invas. 9, 391-423. doi: 10.3391/ai.2014.9.4.01

Rejmánek, M. (2011). "Invasiveness," in Encyclopedia of Biological Invasions, eds D. Simberloff and M. Rejmánek (Berkeley; LosAngeles, CA: University of California Press), 379-385.

Simberloff, D., Martin, J. L., Genovesi, P., Maris, V., Wardle, D. A., Aronson, J., et al. (2013). Impacts of biological invasions: what's what and the way forward. Trends Ecol. Evol. 28, 58-66. doi: 10.1016/j.tree.2012.0 7.013 species introductions and its potential ecological impacts on biodiversity. However, demonstrating ecological impact resulting from the introduction of non-native species is inherently difficult, as the impact can also be indirect through, for instance, the introduction of infectious agents, sexual pheromone pollution, or social network. This is also true since the long (lag) phase may pass before these impacts become apparent. Consequently, it may be highly difficult to foresee ecological impacts before they are eventually identified. This represents one of the most challenging aspects of invasion biology, which requires experimental design procedures to undertake large-scale replicated experiments. Such experiments should be set up using the latest innovative tools within a population level or, preferably, a community/ecosystemlevel approach (e.g., involving dynamic food web modeling) to discriminate yet unseen non-native ecological impacts. The collection in this Research Topic is believed to serve this goal, providing state-of-the art experimental designs and risk assessment tools and models to predict impact of nonnative species.

\section{AUTHOR CONTRIBUTIONS}

All the authors co-edited the Research Topic and approved the final version of editorial.

\section{ACKNOWLEDGMENTS}

The editors would like to thank all the authors of the Research Topic and additional editors for their contributions.

Vilizzi, L., Copp, G. H., Jeffrey, E. H., Adamovich, B., Aislabie, L., Akin, D., et al. (2021) A global-scale screening of non-native aquatic organisms to identify potentially invasive species under current and future climate conditions. Sci. Tot. Environ. 788:147868. doi: 10.1016/j.scitotenv.2021.147868

Conflict of Interest: The authors declare that the research was conducted in the absence of any commercial or financial relationships that could be construed as a potential conflict of interest.

Publisher's Note: All claims expressed in this article are solely those of the authors and do not necessarily represent those of their affiliated organizations, or those of the publisher, the editors and the reviewers. Any product that may be evaluated in this article, or claim that may be made by its manufacturer, is not guaranteed or endorsed by the publisher.

Copyright (c) 2021 Tarkan, Yoğurtçuoğlu, Karachle, Kalogianni, Top Karakuş and Tricarico. This is an open-access article distributed under the terms of the Creative Commons Attribution License (CC BY). The use, distribution or reproduction in other forums is permitted, provided the original author(s) and the copyright owner(s) are credited and that the original publication in this journal is cited, in accordance with accepted academic practice. No use, distribution or reproduction is permitted which does not comply with these terms. 